\title{
Long-term decline in the trophic level of megafauna in the deep Mediterranean Sea: a stable isotopes approach
}

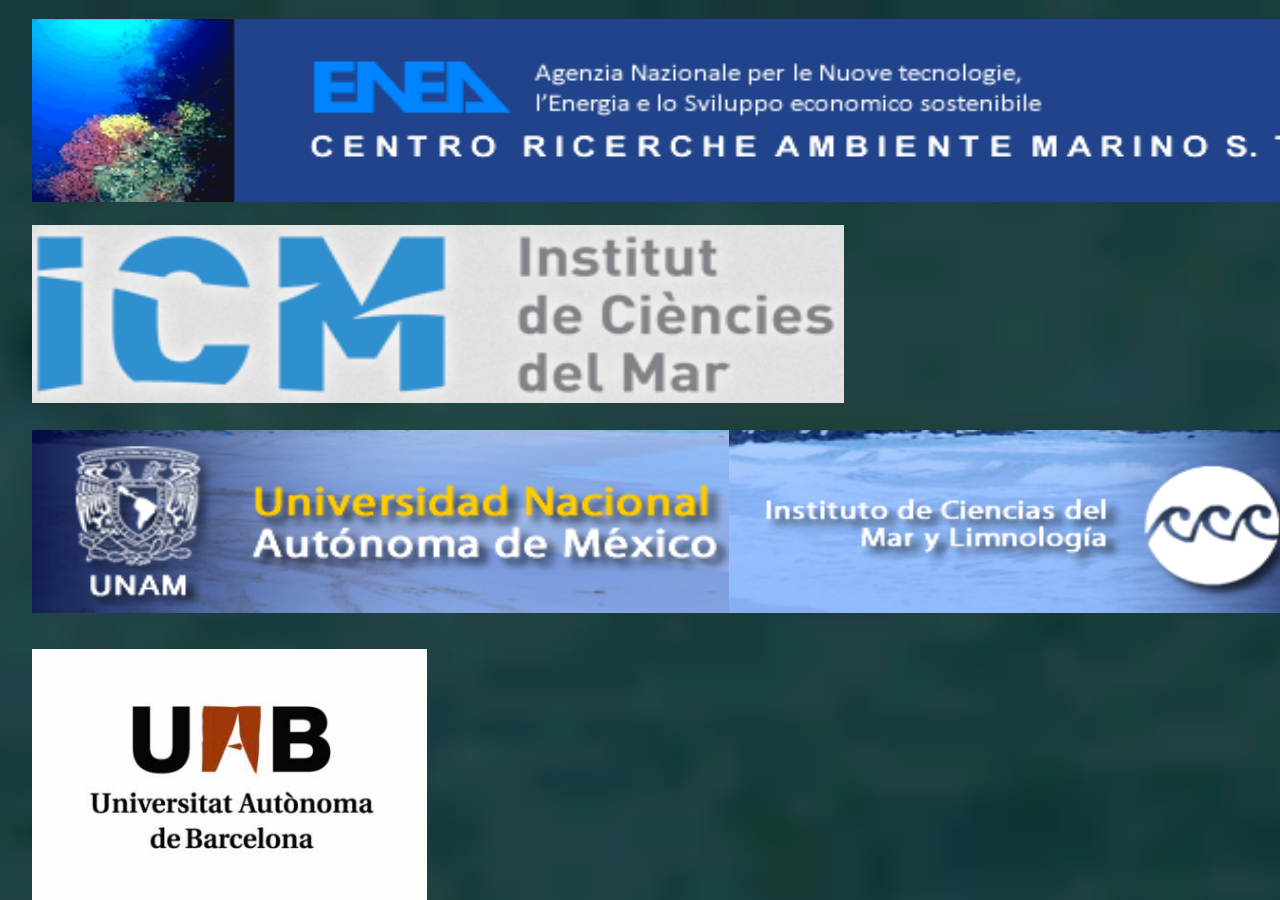

*Contact

emanuela.fanelli@enea.it

Fanelli E. ${ }^{1 *}$,Cartes J.E. ${ }^{2}$, Papiol V. ${ }^{3}$, López-Pérez C. ${ }^{2}$, Carrassón M. ${ }^{4}$

${ }^{1}$ ENEA-CRAM La Spezia, Italy; ${ }^{2}$ ICM-CSIC Barcelona, Spain; ${ }^{3}$ UNAM Mazatlan, Mexico; ${ }^{4}$ UAB Barcelona, Spain

The deep sea was considered a relatively stable environment, buffered from the climatic and geologica drivers that dominate terrestrial and littoral marine ecosystems (Glover et al. 2010). However, climate ariations and sea level oscillations affecting coastal marine communities also have an impact on the deep-sea biota (Glover et al. 2010, Yasuhara et al. 2014), with implications on ecosystem and food webs functioning. Here stable isotopes of carbon and nitrogen of 21 species of deep-sea megafauna (fish, decapods and other invertebrates) collected in two periods separated by ca. 20 years (1985-1989 2007-2011) in the same area were used to:

Assess if the trophic level of megafauna has changed over this period;

Relate such changes to the different hydrographic conditions found in the two periods (i.e.

changes in temperature, salinity, and oxygen in Levantine Intermediate Waters - LIW- and deep water masses).

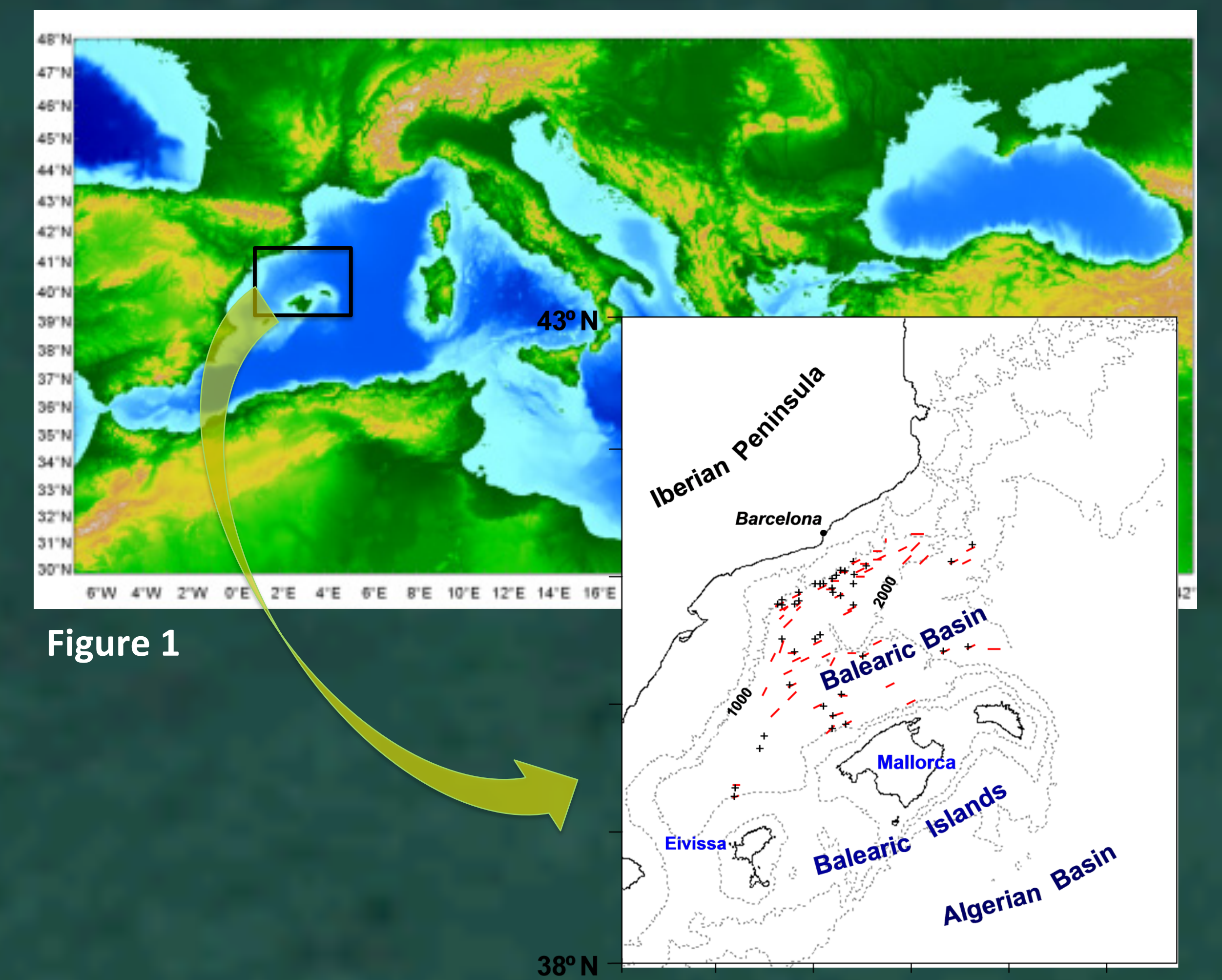

\section{Study area}

were collected within the Species selected for this comparison were those dominant in framework of the Spanish funded projects the megafaunal assemblage in terms of both abundance and BATIMAR, BIOMARE and ANTROMARE biomass (Papiol et al. 2012). For SIA we followed standard (Figure 1). BATIMAR cruises were carried protocols already used for deep-sea macro- and megafauna out in 1985-1989, so we called this "the (see details in Fanelli et al. 2013). '80s period". By contrast, BIOMARE and ANTROMARE cruises were performed in 2007-2011, so we named them "the current period"

Samples were all collected with the same sampler, an OTSB-14 bottom trawl net. In both periods we analysed samples taken between ca. 1000 and $2250 \mathrm{~m}$, at depths free of any fishing activity and at the same stations.
Examples of species analysed for SIA

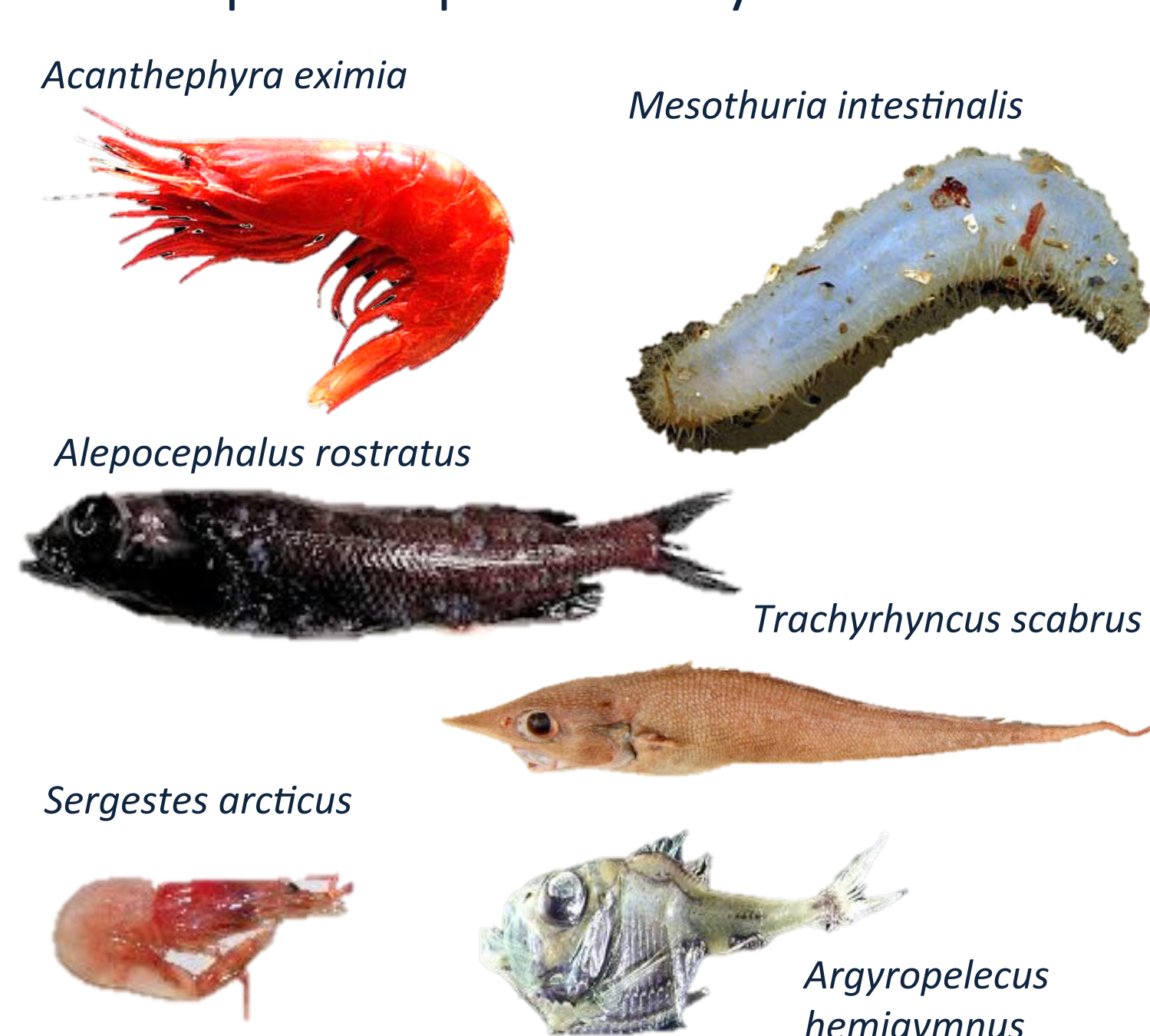

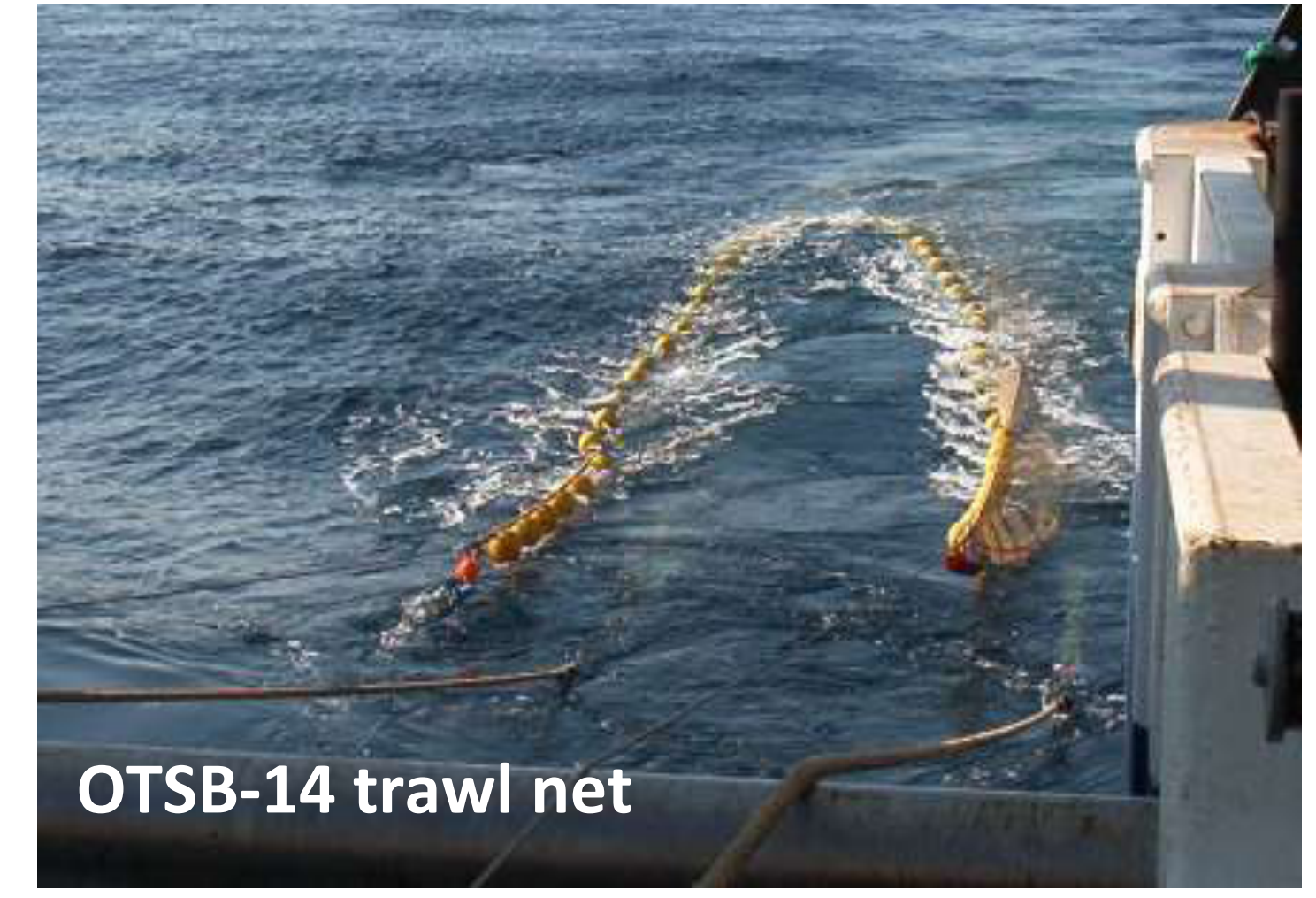

Environmental data collection Temperature $(T)$, salinity $(S)$ and dissolved oxygen $\left(\mathrm{O}_{2}\right)$ near the bottom (in the Benthic Boundary Layer, $\left.\mathrm{O}_{2} \mathrm{BBL}\right)$ and at the LIW core $\left(\mathrm{O}_{2}\right.$ LIW), were obtained in 2007-2011 from CTD casts, while data from 1985-92 were compiled by Cartes et al. (2015), from oceanographic cruises performed in the area in 1984-1993 and from the MEDATLAS database. Possible differences in the climatic regime between the two periods were considered based on winter and annual NAO (North Atlantic Oscillation) indices (http://www.cru.uea.ac.uk). Chlorophyll a concentration (

http://gdata1.sci.gsfc.nasa.gov), as a proxy of food input, and river discharge from the main adjacent rivers were also considered.

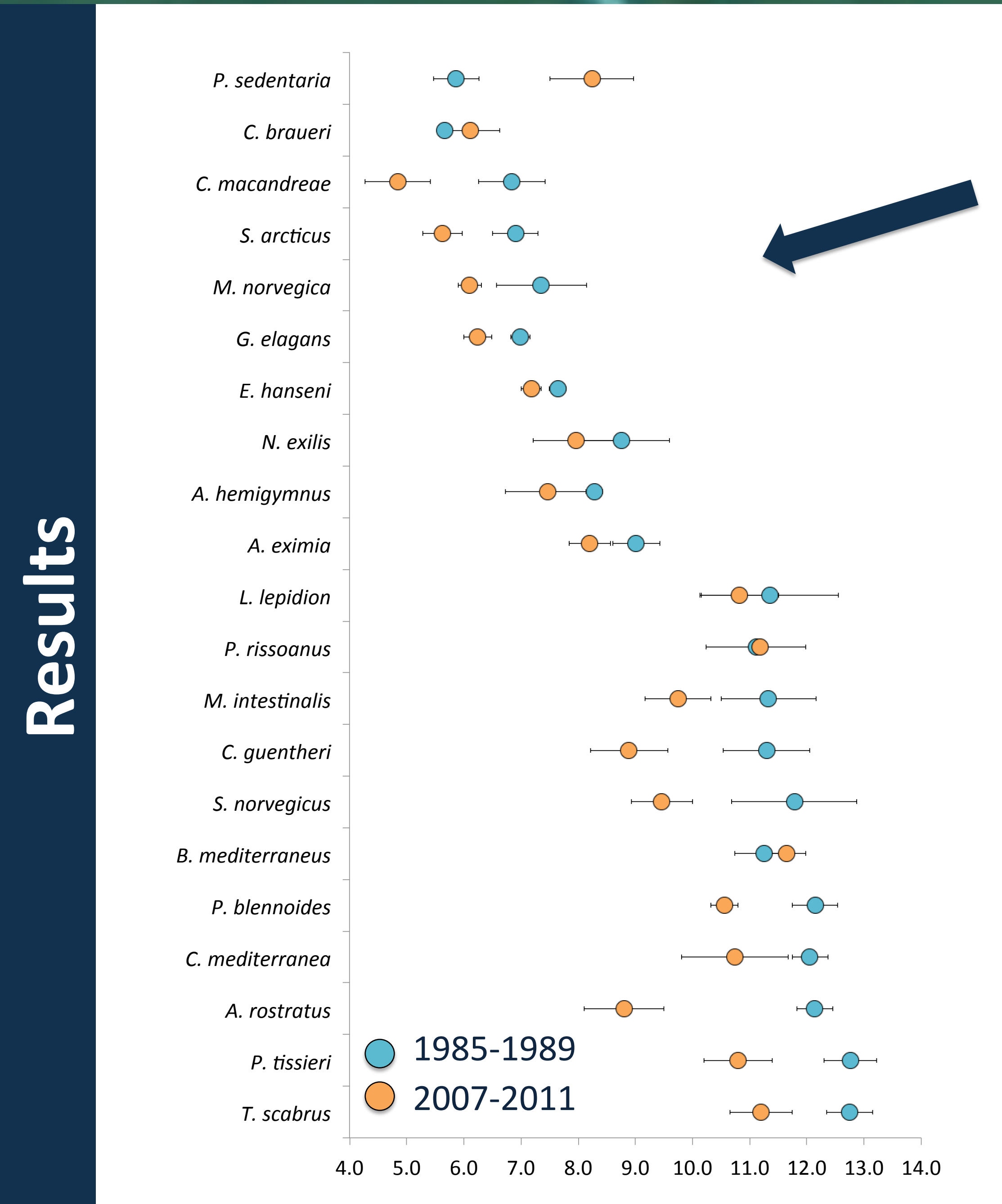

$\delta^{15 \mathrm{~N}}$
Generalized drop of $\delta^{15} \mathrm{~N}$ values between the ' 80 s and the current period in all species, from pelagic organisms $(-0.3 \%$ o ) to benthic invertebrates (-1.3\%) and benthopelagic fishes $(-1.5 \%$ o

Changes in $\delta^{15} \mathrm{~N}$ were linked to $\mathrm{O}_{2}$ decline, both at the core of the Levantine Intermediate Waters (LIW) and on the bottom (BBL), and to increase in salinity

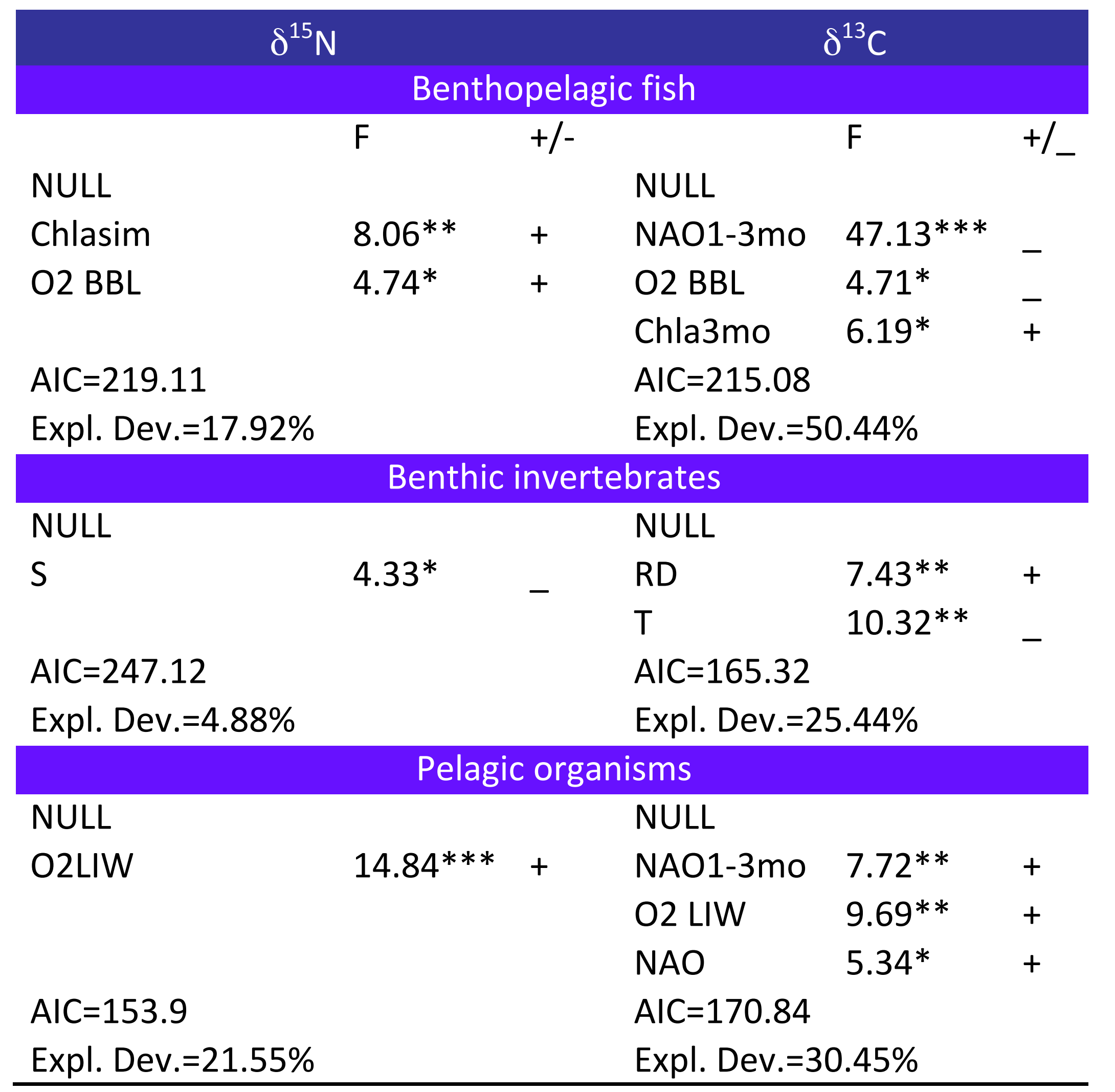

Changes in $\delta^{13} \mathrm{C}$ were mostly related to changes in NAO (North Atlantic Oscillation) index, temperature and $\mathrm{O}_{2}$ both at LIW and at the BBL
Environmental scenario: increase of temperature and salinity from the ' 80 s until now, with a parallel decrease of $\mathrm{O}_{2}$ (both at LIW and $\mathrm{BBL}$ ) and Chlorophyll $a$ concentrations

$$
\begin{aligned}
& 8^{\circ} 80000000000 \\
& \begin{array}{l}
0800000 \\
0 \quad 800000
\end{array} \\
& \text { xygen (bottom) } \\
& 5001000150020002500 \\
& \text { - o o co cocaco } 0 \\
& \cos \varphi^{\circ} 000 \\
& \begin{array}{lll}
500 & 1000 & 1500 \\
2000 & 2500
\end{array}
\end{aligned}
$$

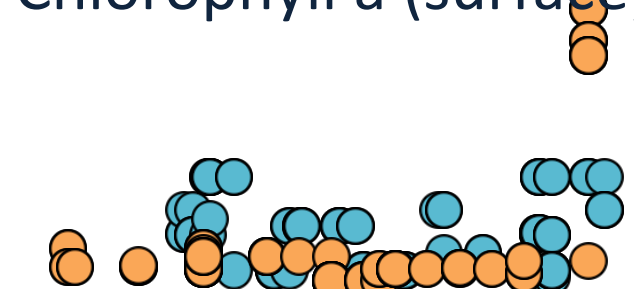

$$
\begin{aligned}
& \begin{array}{lllll}
500 & 1000 & 1500 & 2000 & 2500
\end{array} \\
& \text { Depth }(\mathrm{m})
\end{aligned}
$$

The long-term decline in $\delta^{15} \mathrm{~N}$ in the species analysed, disregarding their trophic level, suggests a generalized drop in the whole food web. Strong relationships between $\delta^{15} \mathrm{~N}$ signature declines with increasing bottom temperatures suggest a shift in diet to prey of lower trophic status in warm years.

The trend observed for practically all organisms (with the exception of formalin-fixed large benthopelagic fishes) is toward greater depletion of ${ }^{13} \mathrm{C}$ in current period samples, in agreement with a greater consumption of zooplankton due to both changes in NAO and the associated increase in zooplankton biomass from 1988 (Piontkovski et al. 2006; Conversi et al. 2010), and to the increase of bottom temperature in turn resulting in lower benthic prey biomass (Cartes et al. 2015).

We hypothesize that the changes in oceanographic conditions, driven in the Mediterranean by both global change and river damming, have influenced benthic organisms by reducing their biomass and/or size, shifting megafaunal predators to more pelagic or smaller benthic prey (i.e., those with lower $\delta^{15} \mathrm{~N}$ values).
Cartes JE, Maynou F, Fanelli E, et al. (2015) J Mar Syst 143:138-153 Conversi A, Fonda Umani S, Peluso T, et al. (2010) PLOS ONE 5(5): e10633 Fanelli E, Papiol V, Cartes JE, et al. (2013) Mar Ecol Prog Ser 490:199-221 Glover AG, Gooday AJ, Bailey DM, et al. (2010) Adv Mar Biol 1-95 Papiol V, Cartes JE, Fanelli E, et al. (2012) Deep-Sea Res I 61:84-99

Piontkovski SA, O'Brien TD, FondaUmani S., et al. (2006) J Plankton Res 28(11): 1039-1046 Yasuhara M, Hunt G, Cronin TM, et al. (2014) Proc Nat Acad Sci 106(51): 21717-21720 